\title{
An Analysis of the implications between the theoretical framework and the policy context of Provincial Education Policy in Ontario
}

\author{
Lorenzo Cherubini \\ Brock University \\ lorenzo.cherubini@brocku.ca
}

\begin{abstract}
Induction is broadly defined in the literature as a formal process of transitioning novice educators into the professional role of teacher. In Ontario, Canada, the establishment of the Education Quality and Accountability Office and large-scale external assessments to measure student learning has underscored the significance of teacher quality. The Ontario Ministry of Education has put into policy that all public school boards deliver the New Teacher Induction Program (NTIP) to new teachers. To a great extent, NTIP includes many of the components discussed in the literature that defines effective practices; however, there are profound implications between the theoretical framework and the policy context of this initiative. This paper discusses the fundamental disconnect between two core concepts associated with NTIP policy that relates to the role of the school principal and to the language of Professional Learning Communities. In essence, the evaluation component of NTIP maintains the traditional hierarchy of schools, reaffirms industrial-type connotations of power, control, and status, and ultimately creates a normative assumption of structure that is deemed to be rational.
\end{abstract}

\section{Introduction}

Over the last several decades in particular there has been an increased awareness of the benefits of supporting new teachers (Breaux \& Worig, 2003; Darling-Hammond, 1995; Wang, Odell \& Schwille, 2008). Induction is broadly defined in the literature as a formal process of transitioning novice educators into the professional role of teacher (Duncan-Poiter, 2005; Sweeny \& DeBolt, 2000). Through a systematic process of professional support and socialization into school culture (Bartell, 2005), new teachers are better able to positively negotiate the array of challenges, including planning effective instruction, accounting for students' learning needs, adhering to district and regional policy, and employing differentiated instruction into their pedagogy (Feiman-Nemser, 2001; Ladson-Billings, 2001). In the absence of induction programs, new teachers are left to cope with the incessant demands of the profession and often resign themselves to mere survival strategies that have an adverse effect upon their instruction and student learning (Henke, Chen \& Geis, 2000; Henke, 2007).

Journal of Contemporary Issues in Education, 2010, 5(1), pp.20-33

ISSN 1718-4770 @ 2010 University of Alberta

http://ojs.educ.ualberta.ca/index.php/jcie/ 
In Ontario, Canada, the establishment of the Education Quality and Accountability Office (EQAO) and large-scale external assessments to measure student learning in grades three, six, and nine has underscored the significance of accountability, and in turn, teacher quality. Similar to the sense of heightened accountability in the United States with the introduction of various policy initiatives (No Child Left Behind Act, 2001, as an example), the mandate to improve teacher performance in Ontario has never been stronger. As a result, the Ontario Ministry of Education (OME) has put into policy that all provincial public school boards deliver the New Teacher Induction Program (NTIP) to new teachers as "the second step in a continuum of professional development for teachers to support effective teaching, learning, and assessment practices, building on and complementing the first step: preservice education programs" (Induction Elements, 2008, p. 5). The OME's commitment to a provincial teacher induction program is praiseworthy, as is the financial investment they have made to implement the program across the province. However, given that the implementation of NTIP is still in its relative infancy, it seems timely to make some observations about the profound potential implications between the theoretical framework and the policy context of this initiative. This discussion may be of relevance to policymakers, district supervisory officers, school administrators, teachers, and teacher federations who are involved with NTIP or other comprehensive teacher induction programs and are interested in supplementing their current practices to enhance the induction experiences of new teachers.

\section{Theoretical Framework}

Effective induction programs aim to improve teacher retention (Wong, 2004) by socializing new teachers into collegial and collaborative school cultures (Schlager, Fusco, Koch, Crawford, \& Phillips, 2003). Supportive school cultures focus their attention on helping new teachers understand the complex relationship between their pedagogy and its influence on student learning (Feiman-Nemser \& Remillard, 1995; Mutchler, 2000). The interplay between these influences also impact upon new teachers' professional behaviour (Ingersoll \& Smith, 2004) and particularly upon their understanding and implementation of school and district policies (Achinstein, Ogawa \& Speiglman, 2004; Grossman \& Thompson, 2004). An extensive body of research has emerged from various conceptual and empirical studies on teacher induction, effective practices, and student learning (Barrington, 2000; Hiebert \& Stigler, 2000). Clearly, schools and school systems that incorporate various collaborative professional networks to foster new teachers' learning capacity are instrumental to their professional development (Goddard, Hoy, Woolfolk Hoy, 2004; Guarion, Santibanez, \& Daley, 2006).

A critical component of teacher induction programs is the successful pairing of protégés with mentor teachers. According to the literature, the extent to which new and mentor teachers establish a trustworthy and professional relationship often determines their success in furthering the new teacher's growth and individual needs (Yusko \& Feiman-Nemser, 2008). This recognizes that mentors need to be knowledgeable and reflective practitioners capable of adequately communicating with the new teacher (Edwards \& Protheroe, 2003; Hagarty, 2000). Mentoring programs that are focused on 
new teacher development assist the mentor to support the novice's transition into the classroom and into the school culture (Strong \& Baron, 2003; Rippon \& Martin, 2003). Mentoring is considered a contextualized practice that is significantly influenced by school culture and curriculum (Hiebert, Gallimore, \& Stigler, 2002). This implies that the mentors have a strong command of inter- and intra-personal skills that complement their innovative teaching practices (Evertson \& Smithey, 2000; Holahan, Jurkat, \& Friedman, 2000). Mentors need to be empathetic towards the challenges that often confront novice teachers and be capable of assisting the protégé to meet the demands of the job (DePaul, 2000).

Feeling supported by the mentor, new teachers can become members of collegial professional school cultures whereby they can exercise a certain degree of initiative and risk-taking as they come to better understand the various facets of their pedagogy and planning (Kearns, 2001). With the confidence of being professionally supported by their mentor and the school community, new teachers can experiment with the strategies learned during their professional development and reflect upon the implications of their practice on student learning, behaviour, and achievement (Totterdell, Heilbronn, Bubb, \& Jones, 2002). In this context, according to the literature, new teachers can engage in fostering both the technical aspects of teaching and the more complex issues of teacherstudent relationships that often entail a more reflective and inward focus (Conway \& Clark, 2003) in a supportive professional environment (McDermott \& O'Dell, 2001). The locus of the school, according to Poulson and Avramidis (2003), situates professional opportunities for new teachers to benefit from mentors and other colleagues. This concept is supported by Lieberman (1996), Harrison (2002), and Spindler and Brott (2000) who advocate for informal and formal learning groups amongst teacher colleagues. As a noteworthy caveat to the above, however, new teachers' learning and professional development is only effective in a school culture that affords novice teachers the necessary conceptual space to make mistakes (Poulson \& Avramidis). Induction interventions that consist of orientation and professional development sessions delivered to new teachers in the absence of any opportunities for reflective practice are not considered measures of progressive assistance (Cibulka, Coursey, Nakayama, Price, \& Stewart, 2000). Characteristic of effective induction programs are those that not only clearly delineate the personnel roles of those involved with its delivery, but also focus to the same extent on new teacher growth as it does on professional development (Arends \& Rigazio-DeGilio, 2000). New teacher growth is nurtured in professional environments wherein teacher practices, experiences, and resources are freely-shared amongst colleagues as a basic ingredient to a supportive, invitational, and non-threatening culture of teaching and learning (Britton, Paine, Pimm, \& Raizen, 2003).

\section{Policy Context}

In Ontario, Canada, the Ministry of Education's (OME) New Teacher Induction Program (NTIP) aims to assist new teachers as they transition from their formal teacher education training to professional teacher. It is designed to complement an individual's theoretical and practical learning acquired during their professional teacher preparation. The NTIP policy stipulates that each publicly-funded school board in Ontario is responsible to provide new teachers with a formal orientation, an experienced teacher 
colleague to serve as a mentor, and the respective training necessary to facilitate OME initiatives. To a great extent, NTIP includes many of the components already discussed in the literature that defines effective practices. Teacher-mentoring relationships (Odell \& Huling, 2000), professional development opportunities catered to new teachers' needs (Cherubini, 2009; Johnson \& Birkeland, 2003), release time for new and mentor teacher conferencing (Hirsch, 2006), and in-services that focus on student learning (Moir \& Gless, 2001), are some examples of the above mentioned components.

The research also cites the importance of how the principal's involvement and understanding of induction policies and programs impacts upon new teachers' experiences (Burch \& Spillane, 2003). According to the NTIP policy, school principals have ten key responsibilities in the delivery of the program. Of the three educational stakeholders who are cited as being directly responsible for NTIP (mentors and supervisory officers represent the other two), the principal's responsibilities are presented in a checklist that includes a descriptive explanation of each of the ten points. The mentor and supervisory officer responsibilities are described in a combined four paragraphs that are quite concise and narrative. The principal's responsibilities are distinctly more delineated. In fact, the policy states that NTIP is "a school-based program in which developing strong professional relationships between principals and new teachers...is instrumental to professional growth" (Induction Elements, 2008, p. 8). Research suggests that principals influence new teachers both directly and indirectly by their actions and beliefs to district and government policies (Coburn, 2005). Principals' actions and manifestations of leadership as they relate to policy contexts can influence new teachers' instructional development (Goldstein, 2004). Principals are responsible for the instructional programs of their school (Newmann, Smith, Allensworth, \& Bryk, 2001) and are themselves under pressure to ensure successful teaching practices in light of the increasing demands of public accountability already discussed (Wahlstom \& Louis, 2008).

Further, NTIP policy commissions school principals to "create and sustain a professional learning community in schools" (Induction Elements, 2008, p. 11). These professional learning communities are described in the policy document as "plentiful opportunities [for new teachers] to engage in professional exchange and collective inquiry that lead to continuous growth and development" (p. 12). The principal is also responsible for, among other things, discussing the Individual NTIP Strategy Form with each new teacher (to ensure that it is reflective of their professional growth throughout the first year), implementing school-based supports for novice teachers, and overseeing the mentor recruitment, selection, and pairing processes. Apart and above from establishing Professional Learning Communities (PLC) in their schools and addressing the key responsibilities, principals are also responsible for "conducting performance appraisals for each new teacher" (p. 14) as it is described in NTIP: Manual for Performance Appraisal of New Teachers (2008). The OME states that this policy is "a companion document to assist with the implementation of the NTIP" (Manual for Performance Appraisals, 2008, p. 5). The companion document also incorporates the language of PLC, and qualifies that in a PLC "teacher performance appraisal is a powerful vehicle for principal and teacher engagement in growth-oriented professional dialogue" (Manual for Performance Appraisals, 2008, p. 29). According to this policy document, 
A meaningful performance appraisal process interacts in a coherent way with the other elements of the NTIP to promote the continuous professional growth and development new teachers need to be successful. (p. 34)

In the above interpretation, thus, school principals are commissioned to nurture PLCs in their school, monitor new teachers' strategies, supervise the mentor/protégé relationship, and formally evaluate new teacher competency and growth.

\section{Discussion}

Effective teacher induction practices enhance new teachers' socialization into the profession, improve their instruction, and foster more productive classroom learning environments. The NTIP policy in Ontario is designed to address the profound challenges presented to new teachers by offering district but predominantly school-based supports, including mentor teachers, to assist new teachers' transition and negotiation of their professional roles and responsibilities. It is critical, however, to make some observations about the various implications between the theoretical framework and the policy context of this provincial initiative. For policy makers, supervisory officers, school administrators, teachers and teacher federations involved with NTIP and other induction programs, the discussion may point to a number of issues that affect new teachers' experiences.

To begin, there seems to be a fundamental disconnect between two core concepts associated with NTIP policy that relates to the role of the school principal. From one perspective, the principal is responsible for fostering professional collaboration amongst new and experienced teachers, tailoring learning opportunities to promote new teachers' professional growth, and establishing a professional relationship with the new teacher based on trust and respect. The policy states that the principal will "work with the new teacher and his or her mentor to determine the content and method of delivery of each element specific to new teacher's needs" (Induction Manual, 2008, p. 10). The literature attests to the significance of collegial and collaborative relationships to support new teachers' learning to teach (Eick, 2002). Principals that model a shared inquiry approach to teaching and learning sustain new teachers' sense of professional development (Rolheiser \& Hundey, 1995). In fact, support from school principals is discussed in the literature as a component of successful teacher induction programs (Lazovsky \& Reichenberg, 2006; Wong, 2004). More specifically, research identifies the importance of principal leadership in terms of providing emotional support for new teachers (Sargent, 2003). Although there has been relatively little research on how principals affect new teachers' practice (Youngs, 2007), it has been determined that principals who model social trust improve teacher collaboration amongst all faculty (Bryk \& Schneider, 2002). Supporting teachers' initiative and working together on professional development initiatives enhances a sense of trust between administrators and teachers (Louise, Kruse, \& Marks, 1996; Spillane, Halverson, \& Diamond, 2001). NTIP clearly states that principals are responsible for cultivating new teacher growth in a supportive and trustworthy manner. The focus on principals to foster growth-oriented professional development for new teachers can hardly be disputed as the administrator's role is to marshal the necessary support for new teachers to flourish in a collegial learning environment based on mutual trust. 
However, the NTIP policy document also positions school principals in an evaluative capacity. They are responsible to conduct two performance appraisals in the first 12 months after the new teacher begins teaching (Induction Manual, 2008, p. 6). Subsequent appraisals are necessary if at the conclusion of the year the new teacher's evaluation is unsatisfactory (Performance Appraisal, 2008, p. 15). This is considered a high-stakes evaluation process since the principal has the authority to recommend termination of the new teacher's employment (Performance Appraisal, p. 53) if they do not meet the requirements of the various enrichment and review plans as articulated in the policy's due process. It seems contradictory that the same individuals responsible for establishing collegial, supportive, and trustworthy relationships with the new teachers are also commissioned to the demands of measuring outcomes where new teachers' jobs are in the balance. One wonders about the feasibility of these two roles harmoniously coexisting so as not to adversely impact new teacher growth and performance in the classroom. It would seem that notions of relationship and evaluation, albeit two necessary considerations, should be directed in separate avenues and interpreted from different perspectives. The concepts of collaboration, trust, and growth associated with the principal's role that resonate in the research literature also surface in NTIP policy, but in fact are significantly undermined by situating the school administrator in a position where their boundaries extend to assuming the role of evaluator. Principals are forced to orchestrate the potentially delicate terrain of meshing social and cultural values that inevitably intersect with the notions of ultimate accountability in respect to their teacher evaluation responsibilities. It seems to compromise the rhetoric of support and trust. One is forced to wonder, therefore, if indeed the induction policy creates the necessary conditions for new teachers to flourish.

A further and somewhat related implication emerges from the concept of Professional Learning Communities (PLC) as they are identified in the policy document. The policy cites "collaboration and relationship-building [as] essential to creating and sustaining a professional learning community in schools" (Induction Elements, 2008, p. 11). The policy suggests that the process of teacher evaluation is actually,

designed to strengthen schools as learning communities in which new teachers are provided with plentiful opportunities to engage in professional exchange and collective inquiry that lead to continuous growth and development. (p. 12) In the same context, the NTIP: Manual for Performance Appraisal of New Teachers (2008) cites the relevant research to substantiate the claim of PLCs as being the most effective means of creating substantive school improvement (p.9). The document states that PLCs "thrive in a culture of sharing, trust, and support" (p. 9). To extend the premise of the previously discussed implication, the rhetoric of the PLC as cited in the policy document would seem once again to be profoundly undermined by embedding its explanation in high-stakes teacher evaluation. Is it realistic to expect new teachers to genuinely and candidly engage in "professional exchanges" and dialogue in a PLC whose membership includes the same school administrator who will ultimately determine their employment status? While new teachers may participate in the various induction inservices and benefit from their mentor in a PLC, the principal's evaluative capacity will potentially influence the professional culture of the PLC itself (Kardos, et al., 2001). By citing the language of the PLC, and be defining the principal's role as evaluator, the NTIP policy may in fact be ignoring the research that discusses the conflicts and residual 
consequences that emerge when professional development initiatives that endorse teacher authority and collaboration clash with hierarchical and bureaucratic realities (Wood, 2007). While the focus on PLC seems to complement trust and collegiality amongst all staff that can positively improve school culture (Bryk \& Schneider, 2003; Louis, 2007), the fact that new teacher evaluation is closely aligned to it suggests a certain degree of disengagement from the true intentions of a PLC.

It is significant to note that professional learning communities have benefited from an extensive body of research discussing teacher and principal perceptions, professional relationships amongst principals and teachers, issues of school improvement, and educational leadership (DuFour \& Eaker, 1998; Mitchell \& Sackney, 2000; Sergiovanni, 2000). PLCs refer to a mode of school organization in which "all stakeholders are involved in joint planning, action, and assessment for student growth and school improvement" (Huffman \& Jacobson, 2003, p. 240). The model is based on participant empowerment that recognizes collaborative leadership (Senge, 1993; Sparks, 1999). The fact that school administrators are expected to evaluate new teachers in the context of a PLC represents competing commitments between the intent of a PLC and their role as evaluators. Given that new teachers are undoubtedly aware that they are being evaluated as a member of a PLC, this would seem to necessitate a shift in their mindset towards skepticism in regards to the significance of "collective inquiry." The new teacher's membership and contributions are, therefore, determined by what is mandated according to the new teacher appraisal process and not necessarily by the values-led spirit of the PLC. According to DuFour and Eaker (1998), collective inquiry requires the membership of the PLC to be "relentless in questioning the status quo, seeking new methods, testing those methods, and then reflecting on the results" (p. 25). How conducive an expectation is it for new teachers to be expected to openly question the status quo in their schools and experiment with different techniques if they are being evaluated during the process? The spirit of PLC requires that individuals are actively oriented and demonstrate "a willingness to experiment" (DuFour \& Eaker, p. 27). According to DuFour and Eaker, such willingness must include "a tolerance for results that may be contrary to what was anticipated" (p. 28). Given the fact that the principal is responsible for the PLC, and that the principal is evaluating the new teacher and determining their future employment, will new teachers manifest this willingness, and, is the notion of tolerance for unanticipated results actually reflected in the appraisal process?

While the reference to the PLC is not necessarily problematic, it is not supported by the practice of the NTIP policy. According to the research, the principal in a PLC "delegates authority, develops collaborative decision-making processes, and steps back from being the central problem-solver....They turn to the professional community for critical decisions" (Louise, Kruse, \& Marks, 1996; as cited in DuFour \& Eaker, p. 186). The literature also suggests that membership in a PLC "cannot be forced" by the school principal, district supervisory officers, or policy initiatives given that, mandating and legislating PLCs sacrifices emergence to the arrogance and overconfidence of imposed design, leading to changes in the designation of schools and districts as learning communities but to no real changes in their nature. (Hargreaves \& Fink, 2006, p. 129) 
The NTIP policy enacts the intent of PLCs, but the filtering of the actual experience for new teachers and principals alike may be markedly different. In the policy's capacity to be pragmatic, the notion of PLC may translate into a more problematic reality. Consider, thus, that "the point of Professional Learning Communities is to commit to and fulfill essential principles and purposes, not to implement other people's specific program priorities" (Hargreaves \& Fink, p. 129).

The NTIP policy is an outcome of what Hargreaves and Fink would describe as the Ontario Ministry of Education's "specific program priorities" as they relate to new teachers and student learning. It has been discussed that the principal's role as evaluator may in fact create a fundamental power imbalance for new teachers who must assume membership in the PLC. The policy also explains that the NTIP Strategy Form, as another example, is to be developed by the new teacher and mentor; yet, the professional development plan is subject to the approval of the principal (Induction Manual, 2008, p. 15). The language of NTIP seems to suggest that new teachers have a significant degree of professional autonomy and individual self-determination. It endorses a valueorientation to new teachers' professional development and growth. Yet, by imposing the evaluative component, the policy may be merely recreating the typical and traditional structure of power relations in the schools and thus taking away from its educative value for the new teacher participants. Wang, Strong, and Odell (2004) concluded that issues of pedagogy, content knowledge, constructive critiques and suggestions to improve new teachers' practices should be the responsibility of the mentor who has a far greater sense of familiarity with the novices' present and future development and growth. In this manner, the school principal can embody supportive and shared leadership, sustain opportunities for shared school values, and empower teachers to assume leadership roles - all characteristics that resonate in the theory of PLC (Darling-Hammond, 2003;

Leithwood, Leonard, \& Sharratt, 1998). By positioning principals as evaluators in the context of a PLC, issues of power, control, and status potentially implicate upon the genuine growth and professional development of new teachers. The risk exists that the process of induction is cultivated in an innovative conceptual framework like PLC, but significantly leveraged by hierarchical and bureaucratic roles.

The institutional roles under discussion imply a certain historical presence. The connection between support and collaboration versus the accountability of formal evaluation procedures offered by the same individual in a position of authority invites a consideration into the multiplicity of power relations. According to Foucault (1972), knowledge is an outcome of discursive practice in what he identified as, "the field of coordination and subordination of statements in which concepts appear and are defined and transferred" (p. 182). During their professional discourse with the principal new teachers may feel compelled to refrain from certain topics at the cost of constraining their employment possibilities. Since power in this context is unilateral, the new teacher may be reluctant to identify shortcomings in their practice and/or interpretations of certain ideologies given their preoccupation with satisfying the criteria of the evaluation process in their relationship with the evaluator. For Foucault (1983), power is a means for individuals to control the other. In this light, "it is a way of acting upon an acting subject...by virtue of their acting or being capable of action" (p. 220). Within these power relations, there exists the potential necessity for principals to expect new teachers to shape their practices according to the evaluator's paradigms; conversely, there is the 
presumed necessity for the new teacher to resign their ideologies to the underlying presumptions of their evaluator. Such an exercise of power invites one to consider if in fact NTIP policy is engineered to optimally perform in its function and purpose.

The OME's initiative, as a defensible and responsible commitment to new teachers and students, becomes subservient to traditional power relations. The appraisal process, as it is intimately connected to the induction program, seems to not only limit the human potential of all the stakeholders involved, but it also becomes synonymous with a top-down and externally imposed policy implementation process. While both teacher evaluation and teacher induction are necessary and dynamic realities, the fact that they are interwoven so tightly in these contexts may under-value the potential PLC's in practice, particularly as far as new teachers' growth and capacities in the classroom is concerned. The coexistence of these two concepts intimate power relationships that affirm the administrator's control in a school. In doing so, it lends itself to the perception that the policy is convincing new teachers that they are being engaged. It risks reinforcing the factory model of school established in the $19^{\text {th }}$ Century that relied on "centralization, standardization, hierarchal top-down management [and] accountability based on adherence to the system" (Hargreaves \& Fink, 2006, pp. 44-45). The tension rests in the fact that principals are simultaneously forced into tow very different roles (Hodkinson, 2006).

\section{Conclusion and Recommendations}

The discussed implications are not meant as criticisms of the Ministry of Education's thoughtful and concerted efforts to support new teachers in Ontario. The vision inherent within the policy that extends into the theory of PLC represents a valueoriented paradigm of supporting teachers' learning and school improvement. It has, however, created various discontinuities for all those invested with the responsibility of better inducting new teachers into the profession in Ontario and possibly beyond. Fundamentally, the evaluation component of NTIP maintains the traditional hierarchy of schools, reaffirms industrial-type connotations of power, control, and status, and ultimately creates a normative assumption of structure that is deemed to be rational. All of this, however, seemingly undermines the ideological outcomes of PLCs. While the policy suggests that teacher performance appraisals are an instrumental means for principal and teacher engagement in professional dialogue (Teacher Appraisal, 2008) under the scope of a PLC, such an engagement is not necessarily an authentic one since new teachers are mandated to complete NTIP as a condition of employment. Teacher evaluation may in fact be the self-declared "powerful vehicle" (p. 29) the policy describes, but it may be more reflective of a forced engagement between principals and teachers in a PLC.

Just as it is a more sustainable strategy for student learning, perhaps new teacher induction programs could position principals to focus on new teacher learning as a first priority and delegate matters of evaluation differently. In this light principals can invest themselves fully in the relational aspects of the PLC and not be perceived by new teachers as the sole individual who determines their employment status. Perhaps an assessment committee, consisting of other educational stakeholders, could be responsible for evaluating the novice's professional development throughout the school year $-\mathrm{a}$ 
practice that has been established in various national and international contexts (Lazovsky \& Reichenberg, 2006). Such an assessment team may consist of a mentor, teacher colleagues, federation representatives, a board administrator, and perhaps the school principal, and may be responsible for assisting the new teacher to formulate a professional development plan, recommend participation in various in-services, review progress reports authored by the new teachers themselves, facilitate cognitive coaching, conduct classroom observations, assist protégés to coordinate a professional portfolio that is subject to evaluation by the assessment team (Koppich, 2005). Leadership, in this light, is more broadly defined and the vision of PLC is far more sustainable. Principals, mentors, teachers, and the entire PLC may be better equipped to enhance their professional capacities and align themselves to the policy's ultimate objective of ensuring student success.

\section{References}

Achinstein, B., Ogawa, R., \& Spielman, A. (2004). Are we creating separate and unequal tracks of teachers? The impact of state policy, local conditions, and teacher characteristics on new teacher socialization. American Educational Research Journal, 41, 557-603.

Arends, R.I. \& Rigazio-Digilio, A.J. (2000). Beginning teacher induction: Research and examples of contemporary practice. Paper presented to the Japan-United States Teacher Education Consortium, United States University, July.

Barrington, R. (2000). An investigation into the induction period which considers the perspectives of NQT's and their tutors. Paper presented at the Annual Conference of the British Educational Research Association, University of Cardiff, Cardiff, Wales.

Bartell, C.A. (2005). Cultivating high quality teaching through induction and mentoring. Thousand Oaks, CA: Corwin Press.

Breaux, A. \& Worig, H. (2003). How to train, support, and retain new teachers. Mountain View, CA: Harry Wong.

Britton, E., Paine, L., Pimm, D., \& Raizen, S. (2003). Comprehensive teacher induction: Systems for early career learning. State, Kluwer Academic Publishers and WestEd).

Bryk, A.S. \& Schneider, B. (2002). Trust in schools: A core resource for improvement. New York: Russell Sage.

Burch, P. \& Spillane, J.P. (2003). Elementary school leadership strategies and subject matter. Elementary School Journal, 103, 519-535.

Cherubini, L. (2009). New teachers' perceptions of induction: Insights into principled practices. The Alberta Journal of Educational Research, 55(2), 185-198.

Cibulka, J.G., Coursey, S., Nakayama, M., Price, J., \& Stewart, S. (2000). Schools as learning organizations: A review of the literature, practitioners guide, and annotated bibliography. Washington, DC: National Partnership for Excellence and Accountability in Teaching.

Coburn, C.E. (2005). Shaping teacher sense-making: School leaders and the enactment of reading policy. Educational Policy, 19, 476-509. 
Conway, P.F. \& Clark, C.M. (2003). The journey inward and outward: A re-examination of Fuller's concerns-based model of teacher development. Teaching and Teacher Education, 19, 465-482.

Darling-Hammond, L. (1995). Changing conceptions of teaching and teacher development. Teacher Education Quarterly, 22(4), 9-26.

Darling-Hammond, L. (2003). Keeping good teachers: Why it matters, what leaders can do. Educational Leadership, 60(8), 6-13.

DePaul, A. (2000). Survival guide for new teachers: How new teachers can work effectively with veteran teachers, principals, and teacher educators. Jessup, MD: US Department of Education, Office of Educational Research and Improvement.

DuFour, R. \& Eaker, R. (1998). Professional learning communities at work. Bloomington, IN: National Education Service.

Duncan-Poitier, J. (2005). Teacher mentoring and induction. New York: New York State Education Department, Office of Teaching Initiatives.

Edwards, A., \& Protheroe, L. (2003). Learning to see in classrooms: What are student teachers learning about teaching and learning while learning to teach in schools? British Educational Research Journal, 29, 227-242.

Eick, C.J. (2002). Job sharing their first year: A narrative of two partnered teachers' induction into middle school science teaching. Teaching and Teacher Education, 18(7), 887-904.

Evertson, C.M. \& Smithey, M.W. (2000). Mentoring effects on protégés' classroom practice: An experimental field study. Journal of Educational Research, 93(5), 294-304.

Feiman-Nemser, S. (2001). Helping novices learn to teach: Lessons from an exemplary support teacher. Journal of Teacher Education, 52(1), 17-30.

Feiman-Nemser, S. (2003). What new teachers need to learn. Educational Leadership, 60(8), $25-29$.

Feiman-Nemser, S. \& Remillard, J. (1995). Perspectives on learning to teach. East Lansing: Michigan State University.

Foucault, M. (1972). The archeology of knowledge. New York: Pantheon Books.

Foucault, M. (1983). Afterward: The subject and power. In H. Dreyfus \& P. Rabinow (Eds.), Michel Foucault: Beyond structuralism and hermeneutics, $2^{\text {nd }}$ edit. Chicago: University of Chicago Press.

Goddard, R.D., Hoy, W.K., \& Woolfolk Hoy, A. (2004). Collective efficacy beliefs: Theoretical developments, empirical evidence, and future directions. Educational Researcher, 33(3), 3-13.

Goldstein, J. (2004). Making sense of distributed leadership. Educational Evaluation and Policy Analysis, 26, 173-197.

Grossman, P.L. \& Thompson, C. (2004). District policy and beginning teachers: A lens on teacher learning. Educational Evaluation and Policy Analysis, 26, 281-301.

Guarino, C.M., Santibanez, L., \& Daley, G.A. (2006). Teacher recruitment and retention: A review of the recent empirical literature. Review of Educational Research, 76(2), 173-208.

Haggarty, L. (2002). What does research tell us about how to prepare teachers? Paper presented at the ESCalate PGGE Conference, University of Notingham, 9 July. 
Hargreaves, A. \& Fink, D. (2006). Sustainable leadership. San Francisco, CA: JosseyBass.

Harrison, J.K. (2002). The induction of newly qualified teachers in secondary schools. Journal of In-Service Education, 28(2), 255-275.

Henke, R.R., Chen, X., \& Geis, S. (2000). Progress through the teacher pipeline: 1992 93 college graduates and elementary/secondary teaching as of 1997 (NCES No. 2000152). Washington, DC: U.S. Department of Education, National Center for Education Statistics.

Hiebert, J., Gallimore, R., \& Stigler, J.W. (2002). A knowledge base for the teaching profession: What would it look like and how can we get one? Educational Researcher, 31(5), 3-15.

Hiebert, J., \& Stigler, J.W. (2000). A proposal for improving classroom teaching: Lessons from the TIMSS video study. Elementary School Journal, 101(1), 3-20.

Hirsch, E. (2006). Recruiting and retaining teachers in Mobile, Alabama: Educators on what it will take to staff all classrooms with quality teachers. Chapel Hill, NC: Center for Teaching Quality.

Hodkinson, A. (2006). Career entry developmental profiles and the statutory induction arrangements in England: A model of effective practice for the professional development of newly qualified teachers. Journal of In-service education, 32(3), 287-300.

Holahan, P.J., Jurkat, M.P., \& Friedman, E.A. (2000). Evaluation of a mentor teacher model for enhancing mathematics instruction through the use of computers. Journal of Research on Computing in Education, 32(3), 336-350.

Huffman, J. \& Jacobson, A. (2003). Perceptions of professional learning communities. International Journal of Leadership in Education, 6(3), 239-250.

Ingersoll, R.M., \& Smith, T. (2004). Do teacher induction and mentoring matter? NASSP Bulletin, 87(638), 28-40.

Johnson, S.M., \& Birkeland, S.E. (2003). Pursuing a sense of success: New teachers explain their career decisions. American Educational Research Journal, 40(3), 581-617.

Kardos, S.M., Moore-Johnson, S., Peske, H.G., Kauffman, D., \& Liu, E. (2001). Counting on colleagues: New teachers encounter the professional cultures of their schools. Educational Administration Quarterly, 37(2), 250-290.

Kearns, H. (2001). Competence-based early professional development: First impressions of the Northern Ireland programme. Journal of In-Service Education, 27(1), 6581.

Koppich, J. (2005). Addressing teacher quality through induction, professional compensation, and evaluation: The effects on labor-management relations. Educational Policy, 19(1), 90-111.

Ladson-Billings, G. (2001). Crossing over to Canaan: The journey of new teachers in diverse classrooms. San Francisco, CA: Jossey-Bass.

Lazovsky, R. \& Reichenberg, R. (2006). Journal of Education for Teaching, 32(1), 5370.

Leithwood, K., Leonard, L., \& Sharratt, L. (1998). Conditions fostering organizational learning in schools. Educational Administration Quarterly, 34(2), 243-276. 
Lieberman, A. (1996). Practices that support teacher development: Transforming conceptions of professional learning. In M.W. McLaughlin \& I. Oberman (Eds.), Teacher learning: New policies, new practices. New York: Teachers College Press.

Louis, K.S. (2007). Trust and improvement in schools. Journal of Educational Change, $8(1), 1-24$.

Louis, K.S., Kruse, S.D., \& Marks, H.M. (1996). School-wide professional community: Teachers' work, intellectual quality, and commitment. In F.M. Newmann \& associates (Eds.), Authentic achievement: Restructuring schools for intellectual quality (pp. 179-203). San Francisco, CA: Jossey Bass.

Mitchell, C. \& Sackney, L. (2000). Profound improvement: Building capacity for a learning community. Lisse: Swets and Zeitlinger.

Moir, E. \& Gless, J. (2001). Quality induction - an investment in teachers. Teacher Education Quarterly, 28(1), 109-114.

Mutchler, S. (2000). Lessons from research on teaching and mentoring: Review of the literature. In Mentoring beginning teachers: Lessons from the experience in Texas. Southwest Educational Development Laboratory. Retrieved October 4, 2008, from http://www.sedl.org/pubs/policy23.

Newmann, F., Smith, B., Allensworth, E., \& Bryk, A. (2001). Instructional program coherence: What it is and why it should guide school improvement policy. Education Evaluation and Policy Analysis, 23(4), 297-322.

Odell, S.J. \& Huling, L. (2000). Quality mentoring for novice teachers. Indianapolis, IN: Kappa Delta Pi.

Ontario Ministry of Education. (2008). New teacher induction program: Induction elements manual. Toronto, ON: Queen's Printer for Ontario.

Ontario Ministry of Education. (2008). New teacher induction program: Manual for performance appraisal of new teachers. Toronto, ON: Queen's Printer for Ontario.

Poulson, L. \& Avramidis, E. (2003). Pathways and possibilities in professional development: Case studies of effective teachers of literacy. British Educational Research Journal, 29(4), 543-560.

Rippon, J., \& Martin, M. (2003). Supporting induction: relationships count. Mentoring and Tutoring, 11(2), 211-226.

Rolheiser, C. \& Hundey, I. (1995). Building norms for professional growth in beginning teachers: A learning consortium initiative. School Effectiveness and School Improvement, 6(3), 205-221.

Sargent, B. (2003). Finding good teachers - and keeping them. Educational Leadership, 60(8), 44-47.

Schlager, M., Fusco, J., Koch, M., Crawford, V. \& Phillips, M. (2003). Designing equity and diversity into online strategies to support new teachers. Paper presented at the National Educational Computing Conference, Seattle, WA: July.

Senge, P.M. (1993). The fifth discipline: The art and practice of the learning organization. New York: Doubleday.

Sergiovanni, T.J. (2000). The lifeworld of leadership: Creating culture, community, and personal meaning in our schools. San Francisco, CA: Jossey-Bass.

Sparks, D. (1999). Overview of the issues. Journal of Staff Development, 18(3), 3. 
Spindler, J. \& Biott, C. (2000). Target setting in the induction of newly qualified teachers: Emerging colleagueship in a context of performance management. Educational Research, 42(3), 275-285.

Strong, M., \& Baron, W. (2004). An analysis of mentoring conversations with beginning teachers: Suggestions and responses. Teaching and Teacher Education, 20, 47-57.

Sweeny, B. \& DeBolt, G. (2000). A survey of the 50 states: Mandated teacher induction programs. In S. Odell \& L. Huling (Eds.), Quality mentoring for novice teachers (pp.97-106). Indianapolis, IN: Kappa Delta Pi.

Totterdell, M., Heilbronn, R., Bubb, S., \& Jones, C. (2002). Evaluation of the effectiveness of the statutory arrangements for the induction of newly qualified teacher. DFES Research Report 338. London, DFES.

United States Federal Law. (2001). No Child Left Behind Act. Public Law (107-110). Washington, DC: Act of Congress.

Wahlstrom, K.L. \& Louis, K.S. (2008). How teachers experience principal leadership: The roles of professional community, trust, efficacy, and shared responsibility. Educational Administration Quarterly, 44(4), 458-495.

Wang, J., Strong, M., \& Odell, S.J. (2004). Mentor-novice conversations about teaching: A comparison of two US and two Chinese cases. Teachers College Record, 106(4), 775-813.

Wang, J., Odell, S.J., \& Schwille, S.A. (2008). Effects of teacher induction on beginning teachers' teaching. Journal of Teacher Education, 59(2), 132-152.

Wong, H. (2004). Induction programmes that keep new teachers teaching and improving. NASPP Bulletin, 88(638), 41-59.

Wood, D. (2007). Teachers' learning communities: Catalysts for change or a new infrastructure for the status quo? Teachers College Record, 109(3), 699-739.

Wynn, S.R., Wilson Carboni, L., \& Patall, E.A. (2007). Beginning teachers' perceptions of mentoring, climate, and leadership: Promoting retention through a learning communities perspective. Leadership and Policy in Schools, 6, 209-229.

Youngs, P. (2007). How elementary principals' beliefs and actions influence new teachers' experiences. Educational Administration Quarterly, 43(1), 101-137.

Yusko, B. \& Feiman-Nemser, S. (2008). Embracing contraries: Combining assistance and assessment in new teacher induction. Teachers College Record, 110(5), 923953. 